\title{
1 The Genetic Architecture of Robustness for Flight Performance in
}

2 Drosophila

Working title: Robustness of flight performance

Adam N. Spierer ${ }^{*}$ and David M. Rand ${ }^{*}$

* Department of Ecology and Evolutionary Biology, Brown University, Providence, RI 02912, USA

\section{Adam N. Spierer}

1280 Waterman St, Providence, RI 02912

13 Adam Spierer@alumni.brown.edu

David M. Rand

1680 Waterman St, Providence, RI 02912

17 David Rand@brown.edu

\section{Author contributions}

DMR and ANS conceived the idea and designed the experiment. ANS performed experiments and analyses. DMR and ANS wrote and revised the manuscript.

\section{Acknowledgements} assistance collecting data, and anonymous reviewers for their feedback. This research was funded by National Institutes of Health grant GM067862 (to DMR).

\section{Data accessibility statement}

All phenotype data required to run the outlined analyses are available in Table S1 or using the DGRP2 webserver (http://dgrp2.gnets.ncsu.edu/). Supplemental tables and files are available at: https://doi.org/10.7910/DVN/RSJNW5.

\section{Conflict of interest statement}

The authors declare no conflict of interest. 


\section{ABSTRACT}

37 A central challenge of quantitative genetics is partitioning phenotypic variation into

38 genetic and non-genetic components. These non-genetic components are usually

39 interpreted as environmental effects; however, variation between genetically identical

40 individuals in a common environment can still exhibit phenotypic variation. A trait's

41 resistance to variation is called robustness, though the genetics underlying it are poorly

42 understood. Accordingly, we performed an association study on a previously studied,

43 whole organism trait: flight performance. Using 197 of the Drosophila Genetic

44 Reference Panel (DGRP) lines, we surveyed variation at the level of single nucleotide

45 polymorphisms and whole genes using additive, marginal, and epistatic analyses that

46 associated with robustness for flight performance. Many genes had developmental and

47 neurodevelopmental annotations, and many more were identified from associations that

48 differed between sexes. Additionally, many genes were pleiotropic, with several

49 annotated for fitness-associated traits (e.g. gametogenesis and courtship). Our results

50 corroborate a previous study for genetic modifiers of micro-environmental variation, and

51 have sizable overlap with studies for modifiers of wing morphology and courtship

52 behavior. These results point to an important and shared role for genetic modifiers of

53 robustness of flight performance affecting development, neurodevelopment, and

54 behavior.

55

56 Keywords: Drosophila Genetic Reference Panel (DGRP), genome wide association

57 study (GWAS), quantitative genetics, flight performance, robustness, behavior 


\section{INTRODUCTION}

60 Evolution acts on the genetic variation underlying phenotypic variation among

61 individuals and populations. While many research programs focus on understanding

62 genetic factors that contribute to phenotypic variation, fewer focus on non-genetic

63 factors. The phenomenon of non-genetic (micro-environmental) variation describes the

64 phenotypic variation that occurs in the absence of genetic variation, best studied in the

65 genetically identical individuals. Non-genetic variation can arise from external

66 (environmental) or internal (developmental) factors. Phenotypic variation across

67 different environmental conditions (e.g. temperature) in genetically homogenous

68 organisms is termed phenotypic plasticity. However, significant phenotypic variation can

69 also arise among genetically homogeneous organisms in the absence of explicit

70 environmental variation. Here, internal factors spur developmental noise in stochastic

71 molecular processes (e.g. important transcripts or signals in very low abundance) that

72 can result in varying levels of developmental stability (ALBAYRAK et al. 2016; SCHOR et

73 al. 2017; KLINGENBERG 2019). The processes or ability for organisms to maintain a

74 consistent phenotype in the presence of these perturbations is termed buffering, while

75 the resulting phenotype is deemed robustness (KLINGENBERG 2019).

77 Developmental noise can affect an organism's developmental trajectory, which may

78 impact the efficacy of natural selection by altering the association between genotype

79 and phenotype. While it is difficult to directly observe developmental noise, deviations

80 from an expected phenotype provide an adequate lens for study (MORGANTE et al. 2015; 
81 VOGT 2015). An example of this is deviations in bilateral symmetry (fluctuating

82 asymmetry) (VALEN 1962; SOTO et al. 2008), which are hypothesized to be negatively

83 associated with fitness in the case of facial symmetry (QUINTO-SANCHEZ et al. 2018;

84 LAJUs et al. 2019). Some genetic safeguards exist to buffer against developmental noise

85 and maintain phenotypic robustness in the presence of these stressors. Chaperonins

86 (HSP90) do so by maintaining a protein's structure during stressful times (RUTHERFORD

87 AND LINDQUIST 1998; CHEN AND WAGNER 2012), as does the mitochondrial unfolded

88 protein response in maintaining homeostasis and promoting longevity (PELLEGRINO et al.

89 2013; JOVAISAITE et al. 2014). In contrast, certain neurodevelopmental cell-cell adhesion

90 molecules (e.g. DSCAMs, cadherins, and teneurins) leverage developmental noise to

91 create more robust neural networks. In doing so, they drive repeatable non-genetic

92 phenotypic variation in behavioral responses to serve as a bet hedging strategy (VOGT

93 et al. 2008; AYROLES et al. 2015; HIESINGER AND HASSAN 2018; HONEGGER AND DE BIVORT

94 2018).

95

96 Genes that modulate a system's ability to resist developmental noise or a stressor are

97 hypothesized evolutionary targets (WAGNER 2008; VoGt 2015; MENEZES et al. 2018) and

98 subject to natural selection. And yet, these sources of non-genetic phenotypic variation

99 are poorly understood. Previous studies have employed a Genome Wide Association

100 Study (GWAS) framework on trait robustness, demonstrating the strategy's feasibility as

101 they identify significant genetic modifiers (KAIN et al. 2012; AYROLEs et al. 2015;

102 Morgante et al. 2015; Menezes et al. 2018; Roman et al. 2018). Similarly, we sought to

103 elucidate these genetic factors by studying the robustness of flight performance in a 
104 GWAS framework. We turned to the Drosophila Genetics Reference Panel (DGRP)

105 lines, a collection of 205 genetically distinct and inbred lines of $D$. melanogaster that

106 represent a snapshot of natural variation in a wild population (MACKAY et al. 2012;

107 HUANG et al. 2014). Using a flight column to test flies' ability to react and respond to an

108 abrupt drop (BENZER 1973; BABCOCK AND GANETZKY 2014), we tested 197 DGRP lines

109 for their mean-normalized standard deviation (coefficient of variation) in flight

110 performance. The coefficient of variation serves as a proxy for studying phenotypic

111 robustness for genetically distinct groups comprised of genetically identical individuals.

112 We identified significant additive, marginal, and epistatic variants, as well as whole gene

113 effects on flight performance, across four sex-based phenotypes (males, females, and

114 the average (sex-average) and difference (sex-difference) between sexes). Using

115 defined insertional mutations in several candidate genes (bru1, CadN, CG15236,

116 CG32181/Adgf-A/Adgf-A2, CG3222, flippy/CG9766, CREG, Dscam4, flapper/CG11073,

117 Form3, fry, Lasp/CG9692, Pde6, Snoo), we successfully validated their gene roles

118 affecting robustness of flight performance. These gene annotations suggest important

119 roles for general and neurodevelopmental processes, and regulation of gene

120 expression. Additionally, we found important roles for pleiotropic genes and fitness-

121 associated genes, suggesting potential sources of developmental noise that may affect

122 developmental stability. Together, these results contribute to a growing body of

123 literature surrounding the genetics of robustness and corroborate previous screens for

124 micro-environmental plasticity (MORGANTE et al. 2015), wing morphology (PITCHERS et

125 al. 2019), and courtship behaviors (TURNER et al. 2013; GAERTNER et al. 2015). 


\section{METHODS}

Drosophila Stocks and Husbandry

129197 Drosophila Genetic Reference Panel (DGRP) lines (HUANG et al. 2014) and 24

130 stocks used in the validation experiment were obtained from Bloomington Drosophila

131 Stock Center (Table S1; https://bdsc.indiana.edu/). Flies were grown on a standard

132 cornmeal media (Mossman et al. 2016) at $25^{\circ}$ under a 12h:12h light-dark cycle. Two to

133 three days post-eclosion, they were sorted by sex under light $\mathrm{CO}_{2}$ anesthesia and given

134 five days to recover before assaying flight performance.

\section{Flight performance assay}

137 We tested approximately 100 flies of each sex from 197 DGRP genotypes (Table S1)

138 using a refined protocol (BABCOCK AND GANETZKY 2014) for measuring flight

139 performance (BENZER 1973). For each sex-genotype combination, groups of 20 flies in

140 five glass vials were knocked down, uncorked, and rapidly inverted down a $25 \mathrm{~cm}$

141 chute. The vials traveled until they reached a stop, at which point flies were ejected into

142 a $100 \mathrm{~cm}$ long by $13.5 \mathrm{~cm}$ wide tube. Freefalling flies instinctively attempt to right

143 themselves and land. A transparent acrylic sheet coated in TangleTrap adhesive lined

144 the inside of the tube and immobilized flies at their respective landing height. The sheet,

145 was removed, pinned to a white poster board, and photographed using a Raspberry Pi

146 (model $3 \mathrm{~B}+$ ) and PiCamera (V2). The positional coordinates were extracted using

147 ImageJ/FIJI's 'Find Maxima' feature with options for a light background and noise

148 tolerance of 30 (SCHINDELIN et al. 2012). The distributions of landing heights for each 
149 sex-genotype combination were used to calculate the mean and standard deviation.

150 The coefficient of variation, or the mean-normalized standard deviation, was used as

151 the final phenotype value to represent robustness.

152

153 Genome wide association mapping

154 Robustness phenotypes (Table S2) were submitted to the DGRP2 webserver for the

155 additive association analysis (http://dgrp2.gnets.ncsu.edu/) (MACKAY et al. 2012; HUANG

156 et al. 2014), which returned association results for four sex-based phenotypes: males,

157 females, average between sexes (sex-average) and difference between sexes (sex-

158 difference). We analyzed $1,901,174$ common variants (minor allele frequency $\geq 0.05$ )

159 using a mixed effect model to account for Wolbachia infection status and presence of

160 five major inversions. Since certain inversions covaried with the robustness phenotype

161 (Table S3), only significance scores from a linear mixed model accounting for

162 Wolbachia status and the presence of five major inversions were considered.

\section{$164 \quad$ Validating candidate genes}

165 Candidate genes (Table S1B) were selected if they were identified from variants

166 identified in the sex-average additive variant screen for mean landing height and if there

167 were publicly available lines containing a Minos enhancer trap ( Mi\{ET1\}) mutational

168 insertion (METAXAKIS et al. 2005) generated by the Drosophila Gene Disruption Project

169 (BELLEN et al. 2011). Experimental and control lines were derived from common

170 isoparental crosses for each candidate gene stock backcrossed for five generations to

171 the respective $\mathrm{w}^{1118}$ or $\mathrm{y}^{1} \mathrm{w}^{67 \mathrm{c} 23}$ background. Isoparental crosses between the resulting 
172 heterozygous offspring were partitioned for absence (control line) or presence

173 (experimental line) of the Mi\{ET1\} construct. Experimental lines were verified for

174 homozygosity if all progeny contained the insertion after several rounds of culturing.

175 Validations were conducting in the flight performance assay described above. The

176 distributions in landing heights were assessed for significance if they passed a $P \leq 0.05$

177 significance threshold in a Kolmogorov-Smirnov test comparing control and mutant

178 genotypes.

\section{Calculating gene-score significance}

181 Gene-level significance scores (gene-score) were determined using PEGASUS_flies

182 (SPIERER et al. 2020), a Drosophila-optimized method for the human-based platform

183 Precise, Efficient Gene Association Score Using SNPs (PEGASUS) (NAKKA et al. 2016).

184 This analysis calculates gene-scores for each gene as a test of whether the distribution

185 of additive variants within a gene (accounting for linkage disequilibrium) deviates from a

186 null chi-squared distribution. Variants from the additive association screen were

187 considered and mapped onto gene annotations and linkage disequilibrium files available

188 with the PEGASUS_flies package_derived initially from the DGRP2 webserver.

190 Screening for epistatic interactions

191 Marginal variants, corresponding with variants more likely to interact with other variants,

192 were identified using MArginal ePlstasis Test (MAPIT) (CRAWFORD et al. 2017). This

193 approach uses a Bayesian framework to test the marginal effect of each variant against

194 a focal phenotype. MAPIT requires a complete genotype-phenotype matrix so the 
195 DGRP genome was imputed for missing variants using BEAGLE 4.1 (BROWNING AND

196 BROWNING 2007; BROWNING AND BROWNING 2016) and filtered for MAF $\geq 0.05$ using

197 VCFtools (v.0.1.16) (DANECEK et al. 2011).

198

199 MAPIT was run using the 'Davies' method on the DGRP2 webserver's adjusted

200 phenotype scores, 1,952,233 imputed and filtered variants, and relatedness and

201 covariate status files available on the DGRP2 webserver

202 (http://dgrp2.gnets.ncsu.edu/data.html). Marginal effect P-values (data available File S8)

203 for each sex-based phenotype were filtered for a Bonferroni threshold $(P<2.56 e-8)$ and

204 served as a focused subset for targeted pairwise epistasis testing against the

205 unimputed variants $(n=1,901,174)$. Epistatic interactions were calculated using the '-

206 epistasis' test in a '-set-by-all' framework in PLINK (v.1.90) (PURCELL et al. 2007).

207 Significant epistatic interactions were considered if they passed a Bonferroni threshold:

2080.05 / ( $\mathrm{n} \times 1901174$ variants), where ' $\mathrm{n}$ ' represents the number of significant marginal

209 variants tested in a sex-specific subset (Table 3).

211 Annotating FBgn and orthologs

212 FB5.57 annotations for FlyBase gene numbers (FBgn) were converted to FB_2020_01

213 annotations using the FlyBase tool 'Upload/Convert IDs' (THURMOND et al. 2019).

214 Updated FBgn (Dmel) were mapped to human orthologs (Hsap) using the Drosophila

215 RNAi Stock Center (DRSC) Integrative Ortholog Prediction Tool (DIOPT)(Hu et al.

216 2011) tool, with the additional filtering parameter: "Return only best match when there is

217 more than one match per input gene or protein." Annotations for various genes without a 
218 citation were done so with auto-generated summaries and unreferenced descriptors of

219 gene functions, expression profiles, and orthologs from FlyBase (GRUMBLING et al. 2006;

220 DOS SANTOS et al. 2015). These descriptors were compiled from data supplied by the

221 Gene Ontology Consortium (ASHBURNER et al. 2000; CARBON et al. 2019), the Berkeley

222 Drosophila Genome Project(FrISE et al. 2010), FlyAtlas (CHINTAPALLI et al. 2007), The

223 Alliance of Genome Resources Consortium (CONSORTIUM 2020), modENCODE (DOS

224 SANTOS et al. 2015), DRSC Integrative Ortholog Prediction Tool (DIOPT) (Hu et al.

225 2011), and Phylogenetic Annotation and INference Tool (PAINT) (GAUDET et al. 2011).

227 Data availability

228 All phenotype data required to run the outlined analyses are available in Table S2 or

229 using the DGRP2 webserver (http://dgrp2.gnets.ncsu.edu/). All supporting information

230 is available at: https://doi.org/10.7910/DVN/RSJNW5. 


\section{RESULTS and DISCUSSION}

233 We sought to identify the genetic modifiers of robustness in a whole organism

234 phenotype: flight performance. Using the Drosophila Genetic Reference Panel (DGRP)

235 lines, we identified several additive, marginal, and epistatic variants, as well as whole

236 genes that associate with genotype robustness in response to a flight challenge. In the

237 sections that follow we describe the variant-based, gene-based, and epistatic analyses

238 in turn.

$240 \quad$ Variation in flight performance across the DGRP

241 We screened 197 DGRP lines (Table S1) for their flight ability in response to an abrupt

242 drop (Figure 1A). Qualitative observations made in a previous study of strong,

243 intermediate, and weak genotypes in the flight assay suggests stronger genotypes react

244 faster and respond more effectively than weaker ones (SPIERER et al. 2020). The mean

245 and standard deviation in landing height were calculated for each sex-genotype

246 combination, along with the mean-normalized standard deviation (coefficient of

247 variation). The coefficient of variation served as our metric for robustness (Figure S1;

248 Table S3). Genotypes with a lower coefficient of variation (more consistent) are more

249 robust for flight performance (KLINGENBERG 2019). On average, flight performance was

250 more robust in males than females (males: 0.17 A.U. \pm 0.055 SD vs. females: 0.22 A.U.

$251 \pm 0.075$ SD; Figures $1 \mathrm{~B}$ and S2). There was a significant relationship in robustness

252 between sexes $(R=0.55 ; P<1 \mathrm{E}-16$; Figure $1 \mathrm{C})$, suggesting the genetic architecture of 
253 robustness in flight performance is similar between the sexes. However, the magnitude

254 of the regression coefficient suggests robustness is somewhat sexual dimorphic.

256 We tested our phenotype in each sex against those publicly available on the DGRP2

257 webserver to determine whether robustness of flight performance was a unique trait.

258 Indeed, we found no significant relationship after applying a multiple testing correction

259 ( $P \leq 1.85 \mathrm{E}-3$; Table S3), suggesting it is unique. Accordingly, we took four distinct

260 approaches to find significant associations from different facets of the genetic

261 architecture (Table 1).

263 Several variants of large effect associate with robustness in flight performance

264 We performed a Genome Wide Association Study (GWAS) to calculate the significance

265 of variants' additive effects, and subsequently whole gene significance scores. We

266 analyzed the effects of $1,901,174$ common variants (MAF $\geq 0.05$ ) across for four sex-

267 based phenotypes (males, females, the sex-average, and sex-difference; Figures 1D

268 and S3-5). Two of the major inversions covaried with our phenotype scores (Table S4),

269 so we used a mixed model to account for Wolbachia infection status, presence of

270 inversions, and polygenic relatedness.

272 We performed a traditional, additive variant screen using the DGRP2 webserver

273 pipeline. Eight variants in the male, female, or sex-average analyses passed a strict

274 Bonferroni threshold ( $P \leq 2.63 \mathrm{E}-8$; Tables 2-4; Table S5). Three variants

275 (2R_17433667_SNP, 3R_4379159_SNP, 3R_9684126_SNP) were also significant for 
276 the mean landing height in flight performance (SPIERER et al. 2020) and mapped to

277 Epidermal Growth Factor Receptor (Egfr; human homolog EGFR), Odorant receptor

$27885 d(\mathrm{Or} 85 d)$ and an intergenic region on chromosome $3 \mathrm{R}$, respectively. Egfr is a

279 pleiotropic, tyrosine kinase receptor involved in several developmental and homeostatic

280 processes, as well as playing a known source of natural variants that modify wing shape

281 and affect flight performance (PAUL et al. 2013; PITCHERS et al. 2019). Or85d is an

282 odorant receptor expressed on the antennae and maxillary palp (CouTo et al. 2005).

283 The significant variant in Or85d coded for a non-synonymous SNP (C277Y) at highly

284 conserved site (Figure S6) (SIEPEL et al. 2005; SIEPEL AND HAUSSLER 2005), though

285 follow up analysis with the PROVEAN webtool (CHOI AND CHAN 2015) suggests this

286 mutation is neutral (scored -2.312 with -2.5 as deleterious). Finally, the intergenic region

287 lacked any embryonic transcription factor binding site (TFBS) annotations (MOSES et al.

288 2006; Ll et al. 2008; MACARTHUR et al. 2009; THOMAS et al. 2011), suggesting it may

289 interact with transcription factors or epigenetic factors later during development or

290 homeostasis.

292 The remaining Bonferroni additive variants mapped to genes that were also identified

293 from additive Bonferroni variants in the mean flight performance screen (Dscam4 and

294 CG11073/flapper) or were otherwise strongly significant (Snoo). These three genes

295 have known or hypothesized roles in developing robust neural circuits (QUIJANO et al.

296 2010; TADROS et al. 2016; SPIERER et al. 2020). Their identification in mean and

297 robustness of flight performance screens suggests they have a dual role in affecting a

298 genotype's ability and variability in flight performance. 
300 Applying a traditional DGRP association threshold ( $P \leq 1 \mathrm{E}-5)$, we observed a trend in

301 our data where neural and pleiotropic genes play an important role in the genetic

302 architecture of robustness of flight performance. We identified 163 unique, significant

303 variants (Table S5), 18 of which mapped to coding regions (Table 4). These coding

304 variants include a novel transcriptional start site in a gene (CG43707) affecting muscle

305 architecture and flight performance (SCHNORRER et al. 2010) and six non-synonymous

306 SNPs that each mapped to unique genes (CG12517, CG13794, CG34215, Or85d, Spn,

307 Tif-IA). Some of these affect neural phenotypes, like CG13794, a neurotransmitter

308 (COUTO et al. 2005; ROMERO-CALDERON et al. 2007), while others are pleiotropic and

309 affect multiple traits. CG12517 and Tif-IA are involved in the stress response of the fat

310 body and insulin-based metabolism, respectively, and both are involved in development

311 of the germline (YATSU et al. 2008; TOOTLE et al. 2011; TSUZUKI et al. 2012; GHOSH et al.

312 2014). Spn (Spinophilin; human homolog PPP1R9A), a pre-synaptic regulator of

313 neurons (MUHAMMAD et al. 2015), affects flight performance (SCHNORRER et al. 2010),

314 male aggression (EDWARDS et al. 2009), odor response (SAMBANDAN et al. 2006), and is

315 also found in sperm (WASBROUGH et al. 2010).

317 Most variants mapped to complex traits with the DGRP are enriched for intergenic and

318 non-coding regions (Table 4) and have presumably regulatory roles (MACKAY et al.

319 2012; MACKAY AND HUANG 2018). Non-coding variants mapped to genes with important

320 roles in development and function of the nervous system, wing morphology, muscle

321 function, and regulation of gene expression. They also play important roles in 
322 gametogenesis or determination of sex identity, establishing a possible connection

323 between genotype and the sexually dimorphic phenotype we measured. A table of all

324 genes found in the current study is available as a master lookup table (File S1). The

325 identification of these genes and their respective annotations may hint at additional

326 genetic sources of developmental stabilization.

328 Functional validation of candidate genes supports a role for neurodevelopment affecting

329 robustness of flight performance

330 We functionally validated several genes' roles in affecting robustness of flight

331 performance. Using insertional mutants in the candidate genes identified from the mean

332 landing height screen, we applied a Kolmogrov-Smirnov test between insert and

333 backcross-control genotypes (see methods) to test for differences in the distribution of

334 landing heights. We validated 11 single genes (bru1, CadN, flippy (CG9766), CG15236,

335 CREG, Dscam4, flapper (CG11073), form3, fry, Pde6, and Snoo), and two constructs

336 that fell in multiple genes (Adgf-A/Adgf-A2/CG32181 and CG9692/Lasp) (Figures 2 and

337 S7; Table S6). These genes are putative sources of genetic variation in maintaining

338 developmental stability. They were also validated in the mean flight performance screen

339 (SPIERER et al. 2020), suggesting these genes likely play dual roles modifying the ability

340 and variability of flight performance.

342 Analyses of whole-gene effects identifies distinct factors affecting robustness

343 The additive variant screen takes a conventional minSNP approach, deeming a gene

344 significant if its most significant variant passes a significance threshold. However, this 
345 approach is biased toward longer genes and does not account for linkage between

346 sites. To counteract these biases, we employed PEGASUS_flies (SPIERER et al. 2020),

347 a Drosophila version of the human-focused PEGASUS platform (NAKKA et al. 2016). This

348 method takes a gene-specific approach; assessing a whole gene's significance by

349 testing the distribution of variants within a gene against a null chi-squared distribution of

350 SNP $P$-values. Thus, it can detect significant genes of moderate effect, as well as genes

351 that may be missed in a minSNP approach.

352

353 Using PEGASUS_flies, we identified 45 unique genes (Table S7) across all four sex-

354 based phenotypes that passed a Bonferroni threshold $(P \leq 3.43 \mathrm{E}-6$; Figures $3 \mathrm{~A}$ and

355 S8). Two were present in the additive screen ( $n m o$ and $S d c$ ), along with 27 other genes

356 with annotations for neurodevelopment and function (ana3, barc, Br140, caps, CG5921,

357 CG5937, CG12163, CG44774, Crz, ct, ctrip, Dop2R, Dys, ena, ham, Nckx30C, Oct-

358 TyR, olf186-F, PsGEF, Ptp4E, rad, rodgi, row, tou, TTLL5, tutl, wde). Some genes also

359 affected muscle, chaete, or general development (caps, CG5937, CG31635, CG32521,

360 CG3277, CG43333), while others facilitated gametogenesis or promoted reproductive

361 success (ana3, CG1632, CG5937, CG12163, CG44774, CHES-1-like, Crz, ct, Dop2R,

362 Dys, ena, Gbs-70E, PsGEF, tou, wde). These results largely corroborate annotations

363 from the additive search and expanded the number of genes that associate with

364 robustness in flight performance. 
368 Epistatic, or pairwise, interactions play an outsized role as context-specific effectors in

369 complex traits (HUANG et al. 2012). Traditional epistasis analyses face large

370 computational and statistical hurdles, so we turned to MArginal ePIstasis Test (MAPIT)

371 to focus the search for interactions (CRAWFORD et al. 2017). MAPIT is a Bayesian

372 approach that identifies marginal variants representing genetic hubs. Using this subset

373 of hub variants, we performed a set-by-all epistasis search against all other variants.

374 We identified 104 significant marginal variants in 66 genes and several intergenic

375 regions that exceeded a Bonferroni threshold $(P \leq 2.56 \mathrm{E}-8)$ across all sex-based

376 phenotypes (Figures 3B and S9; Table S8). Most of these variants mapped to non-

377 coding regions, suggesting an important regulatory role among marginal variants

378 (MACKAY AND HUANG 2018). Among the 19 the significant marginal variants with epistatic

379 interactions (discussed below), only seven mapped to genes (Bx, CG9313, CG15651,

380 CG9171, PKC-ס/Pkcdelta, jvl, ush).

382 In total, there were 6313 significant epistatic interactions that mapped to 1081 genes

383 (Table 3). Interestingly, several of the marginal genes (containing marginal variants) had

384 epistatic interactions with other marginal genes (marginal-marginal epistatic

385 interactions; Figure 4A). However, these interactions were typically between a marginal

386 and non-marginal variant, rather than between two marginal variants. This finding

387 suggests a highly interconnected genetic architecture. Broadly, epistatic interactions

388 were enriched for neurodevelopment and general development, though there were too

389 many significant interactions to comprehensively describe in text (Table S9). Instead, 
390 we will focus on the marginal variants that mapped to genes and some of their

391 noteworthy epistatic interactions.

393 Many marginal variants in female and sex-average epistasis analyses map to pleiotropic

394 genes

395 While the male marginal variant mapped to an intergenic region, there were several

396 marginal variants in the female and sex-average analyses that mapped to genes,

397 especially pleiotropic genes. Among these were Beadex (Bx; human homolog LMO1),

398 CG9171 (human homolog B4GAT1), CG15651 (human homolog FKRP), CG9313, and

399 javelin-like (jvl). The corresponding and significant epistatic interactions, like these

400 marginal genes, have annotations for wing morphology, muscle development, neural

401 circuit assembly and neuronal function, and interestingly, sex-related behaviors and

402 sex-specific tissues (Table S8). For more information on marginal gene functions,

403 please see " Many marginal variants in female and sex-average epistasis analyses map

404 to pleiotropic genes, continued" in the Supplemental Results.

405

406 Epistatic interactions associating with the sex-difference phenotype

407 As noted previously, there was relationship between male and female robustness

408 scores $(R=0.55)$ that suggests a genetic basis for sexual dimorphism. We found a

409 signature of this dimorphism in the sex-difference epistasis search, which had four times

410 as many epistatic interactions as the next closest sex-based phenotype (females). 
412 Protein Kinase $C-\delta(P K C-\delta$ or Pkcd; human homologs PRKCD and PRKCQ) drove this

413 trend and accounted for over half (3211 of 6313) of all epistatic interactions in our study.

414 Some of these interactions were with variants in other marginal genes (Figure 4A),

415 suggesting a more central and interconnected role within the genetic network. PKC- $\delta$ is

416 a member of the Protein Kinase $\mathrm{C}$ family and is known to modulate flies ability to learn

417 from their environment, especially during flight (COLOMB AND BREMBS 2016; GETAHUN et

418 al. 2016; GoRostizA et al. 2016). Flies inability to learn from proprioceptive cues

419 corresponds increased variation in their flight path (HESSELBERG AND LEHMANN 2009;

420 LEHMANN AND BARTUSSEK 2017). Thus, PKC- $\delta$ is a noteworthy candidate gene with a

421 previously validated effect on flight robustness.

423 Another marginal variant from the sex-difference epistasis screen was the

424 developmental transcription factor u-shaped (ush; human homolog ZFPM1), which

425 mediates neurodevelopment and thorax development (FROMENTAL-RAMAIN et al. 2010).

426 It regulates scute (sc), with roles in the sex-determination pathway (WRISCHNIK et al.

427 2003), and the SC-A (scute and achaete) complex, which contributes to development of

428 mechanosensory chaete and sensory organs on the wing (SKEATH AND CARROLL 1991;

429 CUBADDA et al. 1997). Accordingly, ush is similarly a pleiotropic gene that acts as a

430 potential source of developmental noise and stability affecting robustness of flight

431 performance. For more examples and information of epistatic interactions between ush

432 and other genes, see "Epistatic interactions associating with the sex-difference

433 phenotype, continued" in the Supplemental Results. 


\section{Bet hedging as a modifier of robustness}

436 Bet hedging is an evolutionary strategy for increasing phenotypic variation in the

437 presence of genetic homogeneity (HIESINGER AND HASSAN 2018; HONEGGER AND DE

438 BIVORT 2018). We identified putative bet hedging genes involved with

439 neurodevelopment, such as: Down Syndrome Cell Adhesion Molecules (DSCAM;

440 Dscam3 and Dscam4), cadherins (Cad87A, CadN, CadN2), and teneurin (Ten-a) family

441 genes. These genes were also significant interactors with $P K C-\delta$. They contribute to

442 differential wiring of the peripheral and central nervous systems through dendritic self-

443 avoidance (HONG et al. 2012; LI et al. 2020) in the brain and sensory organs of the wing

444 (KISE AND SCHMUCKER 2013; NAGAI AND MIZUNO 2014). Interestingly, Ten-a was

445 previously identified and validated in a screen for individuality in locomotor handedness

446 (AYROLES et al. 2015) and we validated CadN and Dscam4 in the present study.

447 Together, these genes and their roles in differential circuit assembly serve as validated 448 modulators of robustness.

$450 \quad$ Flight and courtship share morphological structures and genetic modifiers

451 Interestingly, we identified several pleiotropic genes with dual roles in robustness of

452 flight performance and courtship and fitness-associated traits. One such gene from the

453 marginal screen was factor of interpulse interval (fipi), a marginal variant with no

454 significant epistatic interactors. This gene regulates the intervals of courtship song

455 (FEDOTOV et al. 2018) and was previously identified in an independent screen for micro-

456 environmental variation (MORGANTE et al. 2015). Other courtship-related studies with the

457 DGRP shared genes with robustness in flight performance (CG1358 and Dif) (TURNER 
et al. 2013) and (bru-3, CG13024, CG42784, Fur1, shot, SKIP, Ubx, wuc) (GAERTNER et al. 2015). We identified several other genes with annotations for sex determination,

460 courtship behavior, and sex-specific neural patterning (Alh, bab1, Btk29A, CASK,

461 chinmo, dnc, dysb, fru, gom, lov, Mip, Nrg, Sh, Tbh), as well as many genes with dual

462 roles in gametogenesis (previously listed).

464 The link between pleiotropic genes association with both fitness-associated traits and

465 robustness of flight performance may lie in the development of common structures. In

466 flight, well-structured wings are important for generating lift (MARCUS 2001) and chaete

467 are important for proprioception (FURMAN AND BUKHARINA 2008; QUIJANO et al. 2010). In

468 courtship, wings are used for visual flagging and courtship song (SADAF et al. 2015),

469 while chaete act as chemosensors for pheromones (THISTLE et al. 2012; PAVLOU AND

470 GoodWIN 2013) and mechanosensors in courtship. Additionally, the neural networks

471 innervating chaete and connecting them to the central nervous system (CNS) are

472 differentially patterned by cell-cell adhesion molecules (e.g. DSCAMS, cadherins, and

473 teneurins) (HONG et al. 2012). We successfully validated Dscam4 and CadN, two such

474 neural patterning genes with important implications in differential detection of

475 pheromones and courtship behaviors (Yu et al. 2010; PAVLOU AND GOODWIN 2013), and

476 flight performance (SPIERER et al. 2020), lending support to our hypothesis.

478 These pleiotropic genes may be associated with robustness as a result of an

479 evolutionary tug-of-war caused by intralocus sexual dimorphism or conflict. In other

480 words, what is beneficial for one sex may be neutral or disadvantageous for the other. 
481 This phenomenon is observed in insects in the context of locomotor performance,

482 courtship behavior, and fitness (BERGER et al. 2014; BERGER et al. 2016). In studies

483 where male flies were allowed to genetically "win" the sex conflict and evolve, males

484 increased locomotor activity, fitness, and variation in wing morphology, while females

485 saw a reduction in locomotor activity and fitness (LONG AND RICE 2007; ABBOTT et al.

486 2010). Variation in wing morphology is noteworthy because it is hypothesized to be

487 under stabilizing selection (MUNOZ-MUNOZ et al. 2016; SZTEPANACZ et al. 2017). It is also

488 sensitive to factors that buffer against developmental noise and serves as a strong

489 proxy for developmental stability (SOTO et al. 2008; KLINGENBERG 2019). Therefore, flies

490 with less within- and between-individual variation in wing morphology are thought to

491 have better buffered genetic networks against developmental noise and stochasticity.

493 Genetic architecture of robustness is comprised of different types of modifiers

494 Each analysis we conducted sheds light on different areas of the genetic architecture

495 (Table 1). The additive variant analysis identified single variants with larger effects on

496 the phenotype, while the whole gene analysis identified genes of moderate effect based

497 on the distribution of additive variants in a gene. The marginal variant analysis identified

498 variants more likely to interact with other variants, while the epistasis analysis identified

499 those respective interactions. Of the variant-based analyses, all additive variants were

500 exclusive, though the marginal variants and epistatic interactions had some overlap

501 (Figure 4B). When mapping these variants to genes, all analyses identified genes that

502 were shared with at least two other analyses (Figure 4C). This result suggests that

503 genes contain different types of variants that affect separate facets of the genetic 
504 architecture. For a complete list of all genes identified in this study and which analysis

505 they were present in, see File S1.

507 Overlap between robustness and other DGRP studies

508 When comparing screens for variants associating with overall flight performance (mean)

509 against robustness for flight performance (coefficient of variation), we consistently

510 identified approximately $15-20 \%$ overlap between variants and their mapped genes

511 (Figure 4D-H; Table S10) with the exception of the whole gene analysis (no overlap;

512 Figure 4I). These results suggest that while certain main features of the genetic

513 architecture are shared, the traits have largely separate genetic architectures.

515 Similarly, we found commonalities between robustness in flight performance and other

516 DGRP studies conducted beyond the flight phenotype. A micro-environmental plasticity

517 screen for startle response, resistance to starvation, and chill coma recovery shared 37

518 genes with robustness of flight performance (Bsg25D, CARPB, CG17716, CG31690,

519 CG32767, CG33981, CG4168, CG42322, CG42324, CG43901, CG5853, Diap1, dpr6,

520 dpr8, E2f1, ed, Eip63E, FAM21, fipi, fred, fru, IA-2, Lac, Lmpt, IncRNA:CR32773,

521 IncRNA:iab8, Moe, mtgo, nub, Pde9, PsGEF, Ptp99A, pum, Pvf3, rdgA, Rgk3, Src64B)

522 (MORGANTE et al. 2015), while a wing morphology screen shared 16 genes (bru1, Bx,

523 CG1358, CG14926, Con, dally, dar1, Dgk, ds, Dys, Egfr, Lar, luna, pip, RhoGEF64C,

524 Sp1) (PITCHERS et al. 2019). The overlap between these studies suggests that modifiers

525 of robustness for flight performance also impact other traits, affirming their pleiotropic

526 nature and their significance in quantitative genetic variation. These findings underscore 
527 the importance of studying the genetic architecture of robustness as it can impact the

528 outcome of natural selection on quantitative traits.

530 Conclusions

531 We present results from four analyses across four sex-based phenotypes surveying

532 different facets of the genetic architecture of robustness for flight performance. Several

533 of the variants were shared between sexes, though many more differed between them.

534 Future studies in other phenotypes should consider evaluating both the mean and

535 coefficient of variation for their focal phenotype to better understand modifiers affecting

536 robustness in a specific complex trait, as well as robustness in complex traits more

537 generally. Doing so would provide a better survey of the genetic modifiers of robustness

538 as a phenotype and allow researchers to glean greater insight into the mechanisms of

539 evolutionary change. 
bioRxiv preprint doi: https://doi.org/10.1101/2020.12.04 412395; this version posted December 6, 2020. The copyright holder for this preprint (which was not certified by peer review) is the author/funder, who has granted bioRxiv a license to display the preprint in perpetuity. It is made available under aCC-BY 4.0 International license.

540

541

Table 1. Different approaches uncover different types of genetic modifiers affecting the focal phenotype. No single screen will identify all modifiers, so four overlapping approaches were conducted to better survey the genetic architecture of robustness of flight performance.

\begin{tabular}{|l|l|l|}
\hline \multicolumn{1}{|c|}{ Screen type } & \multicolumn{1}{c|}{ Target modifier type } & \multicolumn{1}{c|}{ Analysis platform } \\
\hline Additive & Variants of large effect & DGRP2 webserver/FastLMM \\
\hline Marginal & Interconnected variants & MAPIT \\
\hline Epistatic interactions & Connections between variants & PLINK \\
\hline Whole gene & Genes of moderate effect & PEGASUS_flies \\
\hline
\end{tabular}


Table 2. Eight additive variants passed the Bonferroni threshold. In the additive approach, eight variants passed the strict Bonferroni significance threshold $(P \leq 2.63 \mathrm{E}-8)$. These common variants were typically near the Minor Allele Frequency (MAF) threshold of 0.05 . Nearly all variants mapped to genes, three of which had human homologs. Non-coding variants mapped to introns or upstream of the gene's coding region, however three variants also contained transcription factor binding sites (TFBS) annotated active during the embryonic stage (NEGRE et al. 2011).

\begin{tabular}{|c|c|c|c|c|c|}
\hline \multirow[t]{3}{*}{ Variant } & \multirow[t]{3}{*}{ MAF } & \multirow[t]{3}{*}{ Variant type } & \multicolumn{3}{|c|}{ Annotation } \\
\hline & & & \multicolumn{2}{|c|}{ Gene symbol } & \multirow[t]{2}{*}{ Embryonic TFBS } \\
\hline & & & Dmel & Hsap & \\
\hline 2L_7949902_SNP & 0.053 & Intron & Snoo & SKI & \\
\hline 2L_7949906_SNP & 0.053 & Intron & Snoo & SKI & - \\
\hline 2R_17433667_SNP & 0.051 & Intron & Egfr & $E G F R$ & $\begin{array}{l}\text { bcd, da, dl, gt, hb, kni, } \\
\text { Med, prd, sna, tll, twi, } \\
\text { disco, Trl }\end{array}$ \\
\hline 2R_17987191_SNP & 0.067 & Upstream (152 bp) & $\begin{array}{l}\text { Flapperl } \\
\text { CG11073 }\end{array}$ & - & $d l$ \\
\hline 2R_17987203_SNP & 0.062 & Upstream (164 bp) & $\begin{array}{l}\text { Flapperl } \\
\text { CG11073 }\end{array}$ & - & $d l$ \\
\hline 3L_8237797_DEL & 0.084 & Intron & Dscam4 & DSCAM & - \\
\hline 3R_4379159_SNP & 0.053 & Non-synonymous & Or85d & - & - \\
\hline 3R_9684126_SNP & 0.15 & Intergenic & & - & - \\
\hline
\end{tabular}


Table 3. Each analysis and sex-based phenotype identified varying enrichment for genetic modifiers. (A) Additive loci (variants and the genes they map to) at Bonferroni and traditional DGRP GWAS thresholds differ in enrichment by an order of magnitude. (B) Marginal variants mapped to several genes, and were tested for $(C)$ epistatic interactions. Marginal variants were only tested for epistatic interactions if they passed MAF $\geq 0.05$ in the unimputed genome. Finally, (D) whole genes were identified consistently across all sex-based phenotypes

\section{(A) Additive Loci}

\begin{tabular}{|r|c|c|c|c|}
\hline & Male & Female & Sex-Average & Sex-Different \\
\hline $\begin{array}{r}\text { Variants } \\
\text { (Bonferroni; } P \leq 2.63 \mathrm{e}-8)\end{array}$ & 2 & 5 & 4 & 0 \\
\hline $\begin{array}{r}\text { Genes } \\
(\text { Bonferroni; } P \leq 2.63 \mathrm{e}-8)\end{array}$ & 1 & 3 & 3 & 0 \\
\hline $\begin{array}{r}\text { Variants } \\
\text { (Traditional DGRP; } P \leq 1.00 \mathrm{e}-5)\end{array}$ & 75 & 76 & 76 & 21 \\
\hline $\begin{array}{r}\text { Genes } \\
\text { (Traditional DGRP; } P \leq 1.00 \mathrm{e}-5)\end{array}$ & 49 & 62 & 58 & 17 \\
\hline
\end{tabular}

(B) Marginal Loci

\begin{tabular}{|r|c|c|c|c|}
\hline & Male & Female & Sex-Average & Sex-Different \\
\hline $\begin{array}{r}\text { Variants } \\
\text { (Bonferroni; } P \leq 2.56 \mathrm{e}-8)\end{array}$ & 1 & 53 & 19 & 45 \\
\hline $\begin{array}{r}\text { Genes } \\
\text { (Bonferroni; } P \leq 2.56 \mathrm{e}-8)\end{array}$ & 0 & 30 & 11 & 32 \\
\hline
\end{tabular}

(C) Epistatic Loci

\begin{tabular}{|c|c|c|c|c|}
\hline & $\begin{array}{c}\text { Male } \\
(P \leq 2.63 \mathrm{E}-8)\end{array}$ & $\begin{array}{c}\text { Female } \\
(P \leq 5.06 \mathrm{E}-10)\end{array}$ & $\begin{array}{c}\text { Sex-Average } \\
(P \leq 1.34 \mathrm{e}-9)\end{array}$ & $\begin{array}{c}\text { Sex-Different } \\
(P \leq 5.90 \mathrm{e}-10)\end{array}$ \\
\hline $\begin{array}{r}\text { Paired Primary } \\
\text { Variants }\end{array}$ & 1 & 7 & 3 & 8 \\
\hline $\begin{array}{r}\text { Paired Primary } \\
\text { Genes }\end{array}$ & 0 & 3 & 1 & 2 \\
\hline $\begin{array}{r}\text { Paired Secondary } \\
\text { Variants }\end{array}$ & 20 & 428 & 611 & 2019 \\
\hline $\begin{array}{r}\text { Paired Secondary } \\
\text { Genes }\end{array}$ & 13 & 193 & 243 & 763 \\
\hline \multicolumn{5}{|l|}{ (D) Gene-scores } \\
\hline & Male & Female & Sex-Average & Sex-Different \\
\hline $\begin{array}{r}\text { Whole genes } \\
\text { (Bonferroni; } P \leq 3.43 \mathrm{E}-6)\end{array}$ & 10 & 22 & 20 & 10 \\
\hline
\end{tabular}


bioRxiv preprint doi: https://doi.org/10.1101/2020.12.04.412395; this version posted December 6, 2020. The copyright holder for this preprint (which was not certified by peer review) is the author/funder, who has granted bioRxiv a license to display the preprint in perpetuity. It is made available under aCC-BY 4.0 International license.

\begin{tabular}{|c|c|c|c|c|}
\hline Site class & $\begin{array}{l}\text { Additive } \\
(P \leq 2.63 \mathrm{E}-8)\end{array}$ & $\begin{array}{c}\text { Additive } \\
(P \leq 1 \mathrm{E}-5)\end{array}$ & $\begin{array}{l}\text { Marginal } \\
(P \leq 2.56 \mathrm{E}-8)\end{array}$ & $\begin{array}{c}\text { Epistatic } \\
\text { (variable) }\end{array}$ \\
\hline Intergenic & 1 & 25 & 21 & 608 \\
\hline Genic-unique & 7 & 138 & 66 & 2443 \\
\hline Genic-mapped & 7 & 217 & 97 & 3275 \\
\hline Novel start site & 0 & 1 & 0 & 9 \\
\hline Splice site region & 0 & 0 & 0 & 1 \\
\hline $\begin{array}{r}\text { Codon change plus codon } \\
\text { insertion }\end{array}$ & 0 & 0 & 0 & 2 \\
\hline Codon deletion & 0 & 0 & 0 & 1 \\
\hline Non-synonymous coding & 1 & 6 & 1 & 81 \\
\hline Exon (candidate region) & 0 & 3 & 1 & 61 \\
\hline Synonymous coding & 0 & 8 & 7 & 238 \\
\hline Upstream & 2 & 47 & 9 & 462 \\
\hline Downstream & 0 & 24 & 15 & 592 \\
\hline Intron & 4 & 121 & 62 & 1683 \\
\hline 5' UTR & 0 & 1 & 0 & 50 \\
\hline 3' UTR & 0 & 6 & 2 & 95 \\
\hline
\end{tabular}




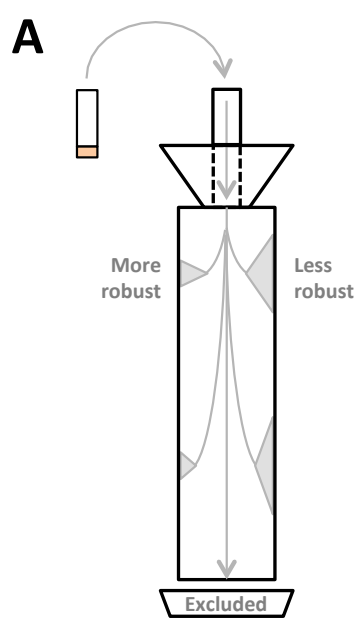

C

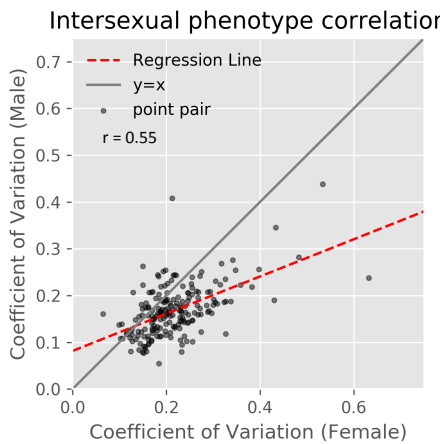

B
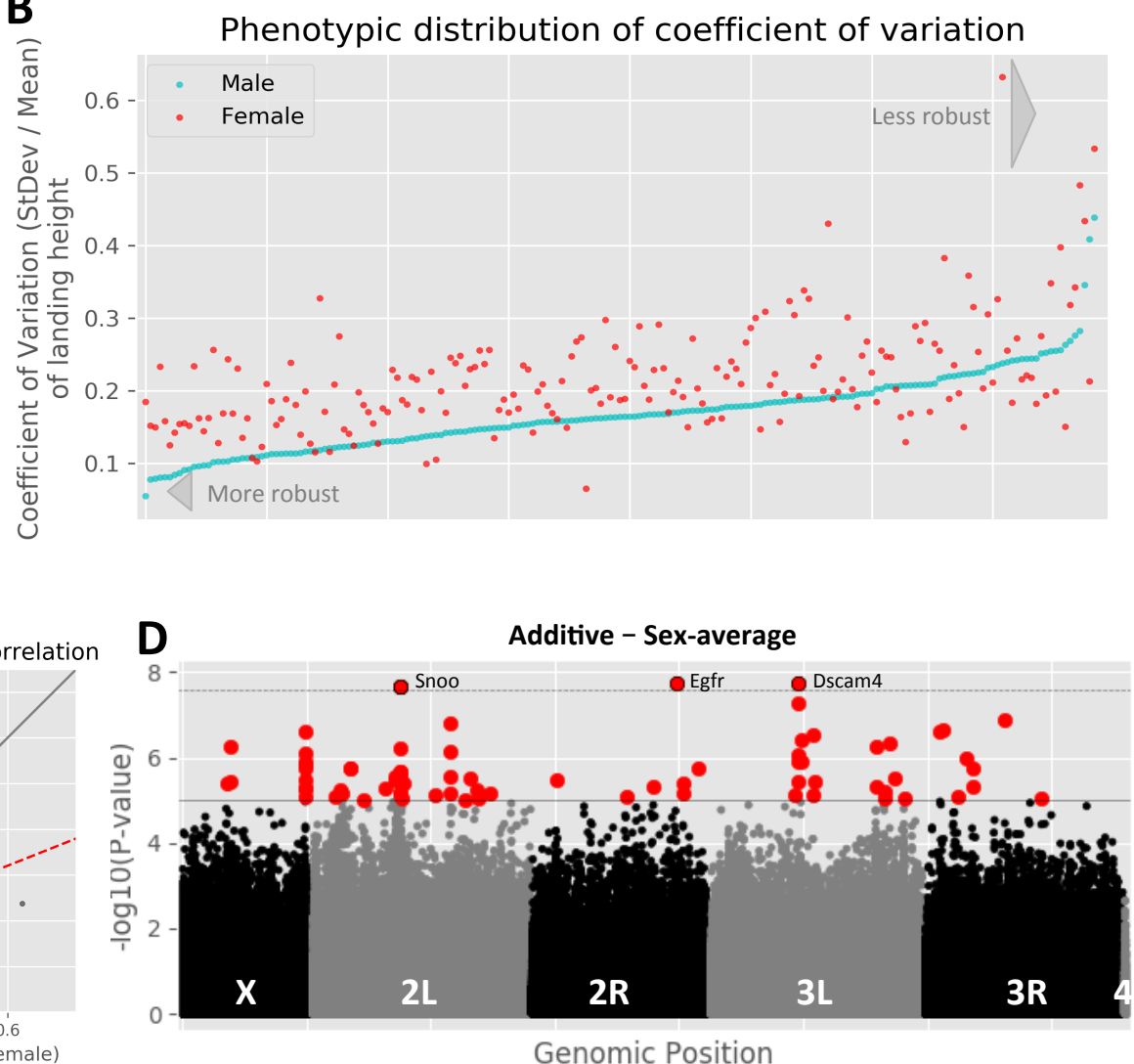

Figure 1. The Drosophila Genetic Reference Panel lines demonstrate variation for robustness in flight performance across genotypes and sexes. (A) Flies were assayed for flight performance using a meter-long flight column (BABCOCK AND GANETZKY 2014). The coefficient of variation (meannormalized standard deviation) is a proxy for robustness; more robust genotypes have less variation in landing height around the mean. Flies that passed through the column were excluded from the analysis. (B) The phenotypic distribution of sex-genotype pairs, ordered by increasing male score, demonstrates the DGRP lines have variation in their robustness for flight performance. Genotypes demonstrated phenotypic variation for robustness in both sexes. (C) Males were generally more robust than females, though the two were related $(\mathrm{R}=0.55, P<1 \mathrm{E}-16$; regression line in red). Sexual dimorphism is observed by the intersection of the regression line and $y=x$ line (gray). (D) Additive variants in the sex-average analysis, visualized as a function of the - $\log 10$ of variants' $P$-value illustrates several variants (red) passed the traditional DGRP significance threshold $(P \leq 1 \mathrm{E}-5$; gray solid line), and three (red with black outline) passed Bonferroni significance threshold ( $P \leq 2.63 \mathrm{E}-8$, gray dashed line). Variants that did not pass the significance threshold are colored in black or gray by chromosome. 


\section{Functional validation of candidate genes}

A Difference in Coefficient of Variation: Male

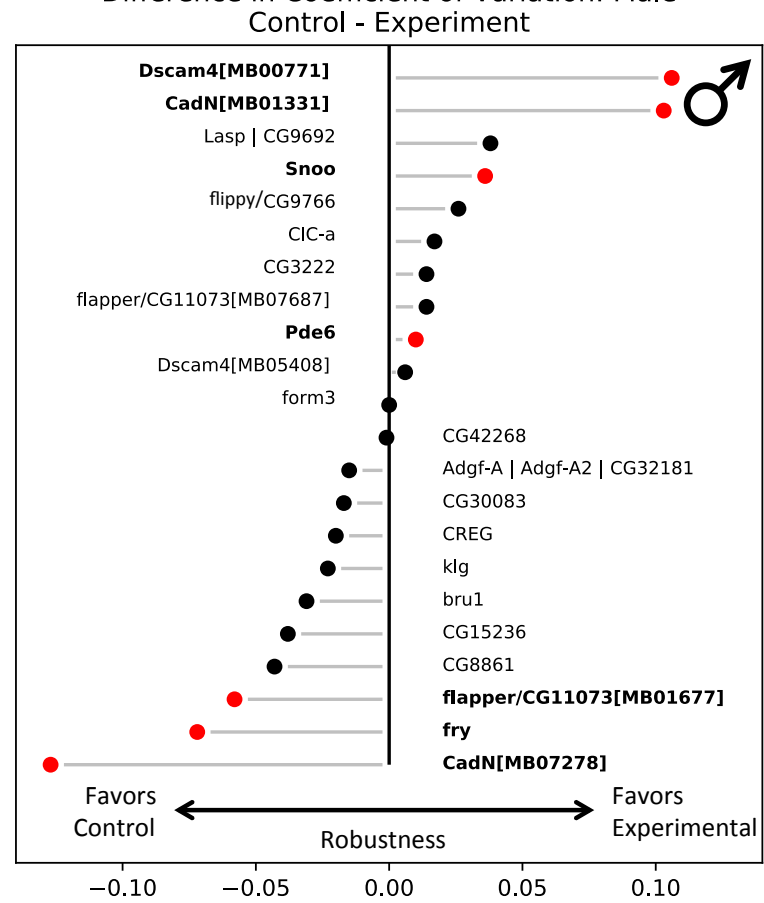

B Difference in Coefficient of Variation: Female

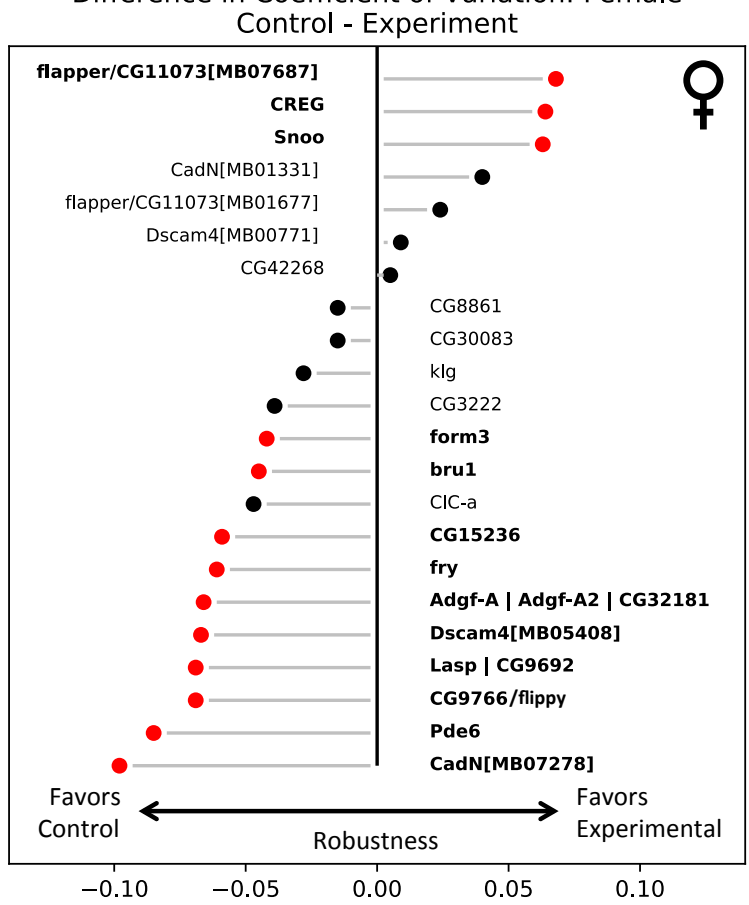

Figure 2. Several genes validated for robustness of flight performance. Flies homozygous for Mi\{ET1\} insertion constructs inserted in candidate genes (experiment) were tested against their background control (control). Comparisons between control and experiment lines were assessed for significance using a Kolmogrov-Smirnoff test $(P \leq 0.05$; red points and bold text). Values to the left of the midline suggest control genotypes were more robust than experimental lines, while the opposite is true for values to the right of the line. (A) Seven constructs were significant in males, (B) while 13 were significant in females. Some candidate genes were tested more than once (CadN, Dscam4, and flapper) because they were strongly significant in the sex-average additive association screen. Separate constructs are denoted by a suffix containing a 'MB' code. 


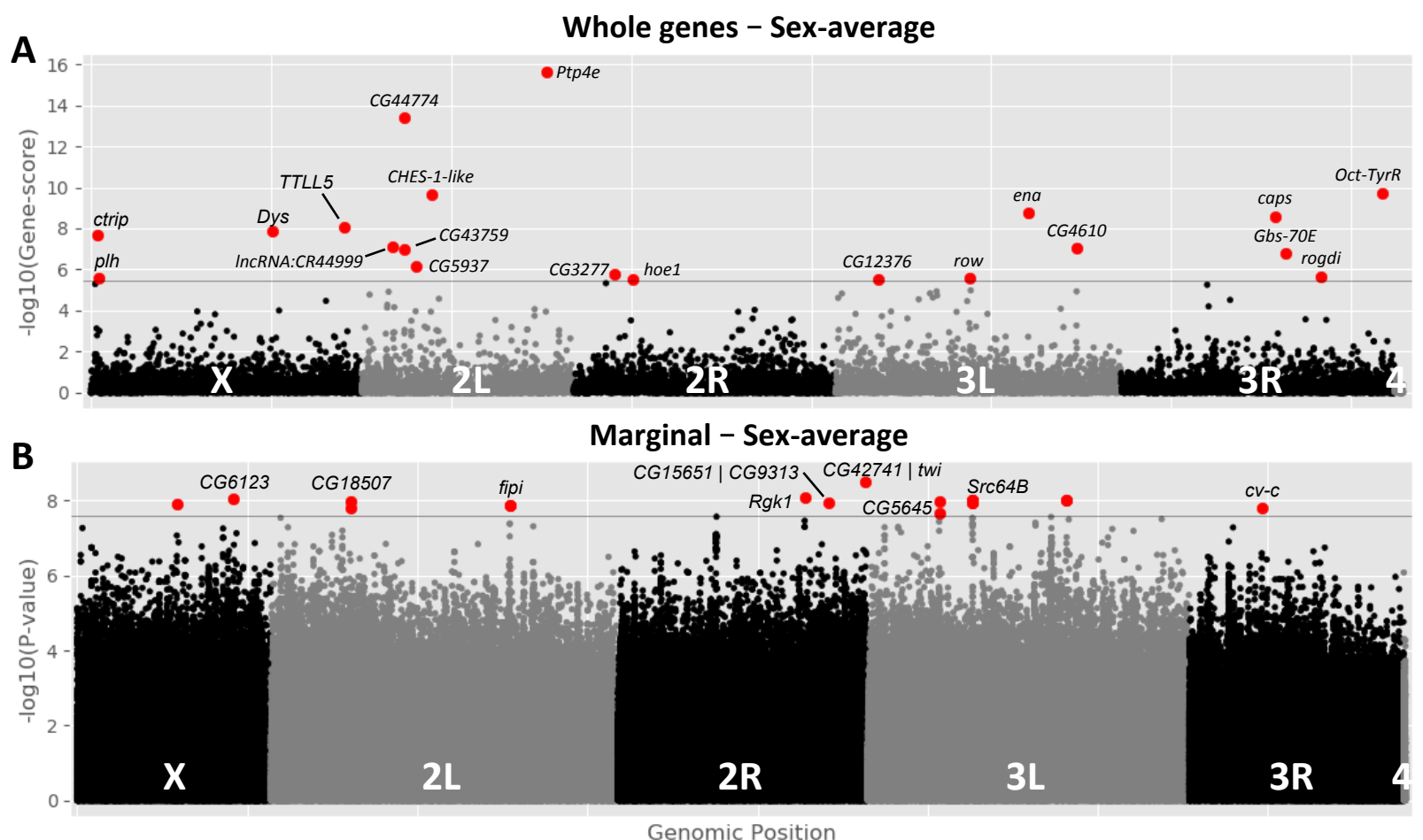

Figure 3. Several genetic variants positively associate with flight performance across different types of analyses. (A) Manhattan plot for sex-average whole gene analysis suggests several genes (red) were significant above a Bonferroni threshold ( $P \leq 3.43 \mathrm{E}-6$, gray line). (B) Manhattan plot for sexaverage marginal analysis suggests several variants (red) were significant above a Bonferroni threshold $(P \leq 2.56 \mathrm{E}-8$, gray line). For each plot, points are arranged by relative chromosome (genomic) position and all points are -log10 transformed. 
A

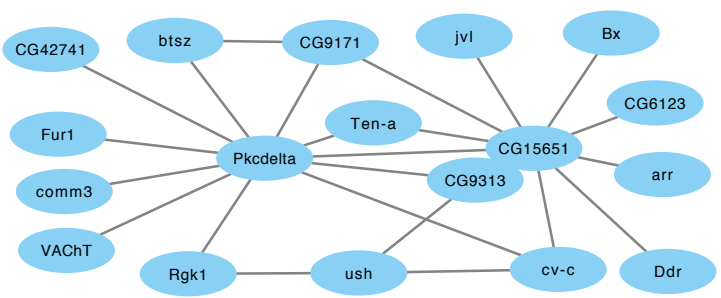

B

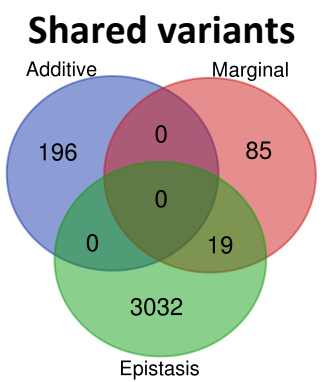

C

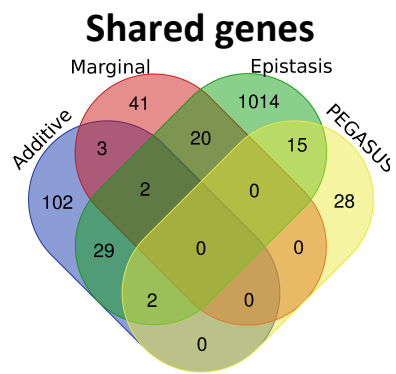

$\mathbf{F}$

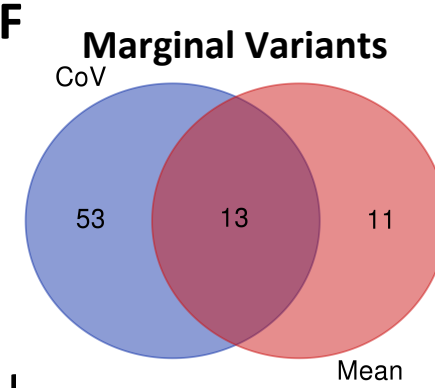

I

H
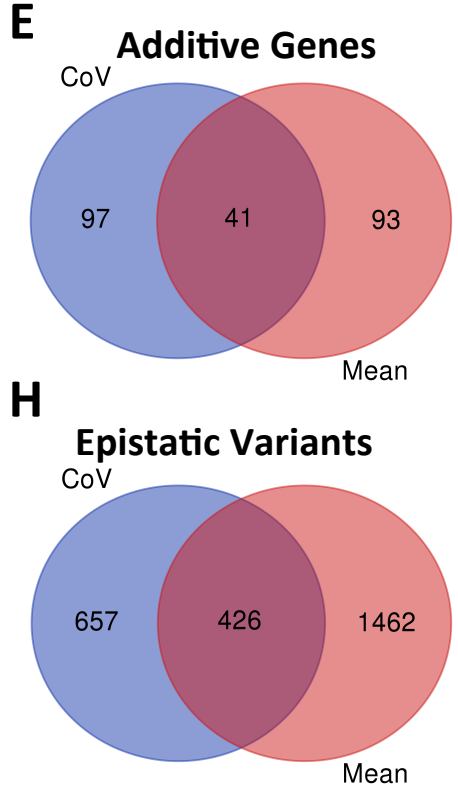

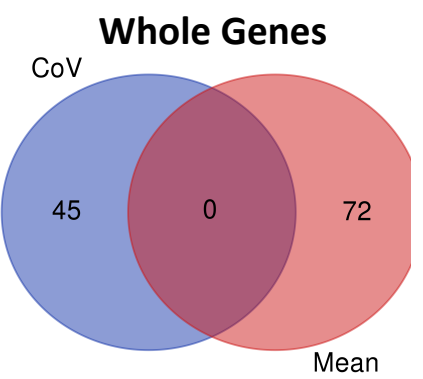

Figure 4. Robustness of flight performance is comprised of an interconnected genetic architecture. (A) There were several interactions between genes identified from marginal variants. In particular, $P K C-\delta$ had the greatest number of interactions with other marginal genes, while CG15651 and CG9313 were next. There was a marginal variant that overlapped with CG15651 and CG9313, so all edges connecting to CG15651 also connect to CG9313, however there was an independent variant in CG9313 that did not overlap with CG15651 that interacted in the sex-difference screen with $P C K-\delta$ and ush. Intergenic regions that also interacted with genic marginal variants are not displayed. (B) For the additive, marginal, and epistatic variants identified, additive variants were unique, while marginal and epistatic variants had some overlap. This overlap was expected since the marginal variants served as a subset in searching for epistatic variants. (C) Genes and genes mapped from minSNP-variants had some overlap between analyses, though most genes were unique to a single analysis. When comparing variants and unique genes across (D-E) additive, marginal $(F-G)$, and epistatic $(H)$ analyses, there was roughly $15-20 \%$ overlap between the shared group and all those identified. However, there was no overlap between the (I) whole genes identified using PEGASUS_flies. 


\section{Literature Cited}

Abbott, J. K., S. Bedhomme and A. K. Chippindale, 2010 Sexual conflict in wing size and shape in Drosophila melanogaster. Journal of Evolutionary Biology 23: 19891997.

Albayrak, C., C. A. Jordi, C. Zechner, J. Lin, C. A. Bichsel et al., 2016 Digital Quantification of Proteins and mRNA in Single Mammalian Cells. Molecular Cell 61: 914-924.

Ashburner, M., C. A. Ball, J. A. Blake, D. Botstein, H. Butler et al., 2000 Gene Ontology: tool for the unification of biology. Nature Genetics 25: 25-29.

Ayroles, J. F., S. M. Buchanan, C. O'Leary, K. Skutt-Kakaria, J. K. Grenier et al., 2015 Behavioral idiosyncrasy reveals genetic control of phenotypic variability. Proceedings of the National Academy of Sciences of the United States of America 112: 6706-6711.

Babcock, D. T., and B. Ganetzky, 2014 An Improved Method for Accurate and Rapid Measurement of Flight Performance in Drosophila. Jove-Journal of Visualized Experiments.

Bellen, H. J., R. W. Levis, Y. C. He, J. W. Carlson, M. Evans-Holm et al., 2011 The Drosophila Gene Disruption Project: Progress Using Transposons With Distinctive Site Specificities. Genetics 188: 731-U341.

Benzer, S., 1973 GENETIC DISSECTION OF BEHAVIOR. Scientific American 229: 2437.

Berger, D., E. C. Berg, W. Widegren, G. Arnqvist and A. A. Maklakov, 2014 Multivariate intralocus sexual conflict in seed beetles. Evolution 68: 3457-3469.

Berger, D., T. You, M. R. Minano, K. Grieshop, M. I. Lind et al., 2016 Sexually antagonistic selection on genetic variation underlying both male and female same-sex sexual behavior. Bmc Evolutionary Biology 16.

Brockington, M., Y. Yuva, P. Prandini, S. C. Brown, S. Torelli et al., 2001 Mutations in the fukutin-related protein gene (FKRP) identify limb girdle muscular dystrophy 2 I as a milder allelic variant of congenital muscular dystrophy MDC1C. Human Molecular Genetics 10: 2851-2859.

Browning, B. L., and S. R. Browning, 2016 Genotype Imputation with Millions of Reference Samples. American Journal of Human Genetics 98: 116-126.

Browning, S. R., and B. L. Browning, 2007 Rapid and accurate haplotype phasing and missing-data inference for whole-genome association studies by use of localized haplotype clustering. American Journal of Human Genetics 81: 1084-1097.

Carbon, S., E. Douglass, N. Dunn, B. Good, N. L. Harris et al., 2019 The Gene Ontology Resource: 20 years and still GOing strong. Nucleic Acids Research 47: D330-D338.

Chen, B., and A. Wagner, 2012 Hsp90 is important for fecundity, longevity, and buffering of cryptic deleterious variation in wild fly populations. BMC evolutionary biology 12: 25.

Chintapalli, V. R., J. Wang and J. A. T. Dow, 2007 Using FlyAtlas to identify better Drosophila melanogaster models of human disease. Nature Genetics 39: 715720. 
Choi, Y., and A. P. Chan, 2015 PROVEAN web server: a tool to predict the functional effect of amino acid substitutions and indels. Bioinformatics 31: 2745-2747.

Colomb, J., and B. Brembs, 2016 PKC in motorneurons underlies self learning, a form of motor learning in Drosophila. Peerj 4.

Consortium, T. A. O. G. R., 2020 Alliance of Genome Resources Portal: unified model organism research platform. Nucleic acids research 48: D650-D658.

Couto, A., M. Alenius and B. J. Dickson, 2005 Molecular, anatomical, and functional organization of the Drosophila olfactory system. Current Biology 15: 1535-1547.

Crawford, L., P. Zeng, S. Mukherjee and X. Zhou, 2017 Detecting epistasis with the marginal epistasis test in genetic mapping studies of quantitative traits. Plos Genetics 13.

Cubadda, Y., P. Heitzler, R. P. Ray, M. Bourouis, P. Ramain et al., 1997 u-shaped encodes a zinc finger protein that regulates the proneural genes achaete and scute during the formation of bristles in Drosophila. Genes \& Development 11: 3083-3095.

Danecek, P., A. Auton, G. Abecasis, C. A. Albers, E. Banks et al., 2011 The variant call format and VCFtools. Bioinformatics 27: 2156-2158.

dos Santos, G., A. J. Schroeder, J. L. Goodman, V. B. Strelets, M. A. Crosby et al., 2015 FlyBase: introduction of the Drosophila melanogaster Release 6 reference genome assembly and large-scale migration of genome annotations. Nucleic Acids Research 43: D690-D697.

Edwards, A. C., L. Zwarts, A. Yamamoto, P. Callaerts and T. F. Mackay, 2009 Mutations in many genes affect aggressive behavior in Drosophila melanogaster. BMC biology 7: 29.

Fedotov, S. A., J. V. Bragina, N. G. Besedina, L. V. Danilenkova, E. A. Kamysheva et al., 2018 Gene CG15630 (fipi) is involved in regulation of the interpulse interval in Drosophila courtship song. Journal of Neurogenetics 32: 15-26.

Frise, E., A. S. Hammonds and S. E. Celniker, 2010 Systematic image-driven analysis of the spatial Drosophila embryonic expression landscape. Molecular Systems Biology 6.

Fromental-Ramain, C., N. Taquet and P. Ramain, 2010 Transcriptional interactions between the pannier isoforms and the cofactor U-shaped during neural development in Drosophila. Mechanisms of Development 127: 442-457.

Furman, D., and T. Bukharina, 2008 How Drosophila melanogaster forms its mechanoreceptors. Current genomics 9: 312-323.

Gaertner, B. E., E. A. Ruedi, L. J. McCoy, J. M. Moore, M. F. Wolfner et al., 2015 Heritable Variation in Courtship Patterns in Drosophila melanogaster. G3-Genes Genomes Genetics 5: 531-539.

Gaudet, P., M. S. Livstone, S. E. Lewis and P. D. Thomas, 2011 Phylogenetic-based propagation of functional annotations within the Gene Ontology consortium. Briefings in Bioinformatics 12: 449-462.

Getahun, M. N., M. Thoma, S. Lavista-Llanos, I. Keesey, R. A. Fandino et al., 2016 Intracellular regulation of the insect chemoreceptor complex impacts odour localization in flying insects. Journal of Experimental Biology 219: 3428-3438. 
641

642

643

644

645

646

647

648

649

650

651

652

653

654

655

656

657

658

659

660

661

662

663

664

665

666

667

668

669

670

671

672

673

674

675

676

677

678

679

680

681

682

683

684

685
Ghosh, A., E. J. Rideout and S. S. Grewal, 2014 TIF-IA-Dependent Regulation of Ribosome Synthesis in Drosophila Muscle Is Required to Maintain Systemic Insulin Signaling and Larval Growth. Plos Genetics 10.

Gorostiza, E. A., J. Colomb and B. Brembs, 2016 A decision underlies phototaxis in an insect. Open Biology 6.

Grumbling, G., V. Strelets and C. FlyBase, 2006 FlyBase: anatomical data, images and queries. Nucleic Acids Research 34: D484-D488.

Hesselberg, T., and F. O. Lehmann, 2009 The role of experience in flight behaviour of Drosophila. Journal of Experimental Biology 212: 3377-3386.

Hiesinger, P. R., and B. A. Hassan, 2018 The Evolution of Variability and Robustness in Neural Development. Trends in Neurosciences 41: 577-586.

Honegger, K., and B. de Bivort, 2018 Stochasticity, individuality and behavior. Current Biology 28: R8-R12.

Hong, W. Z., T. J. Mosca and L. Q. Luo, 2012 Teneurins instruct synaptic partner matching in an olfactory map. Nature 484: 201-+.

Hu, Y. H., I. Flockhart, A. Vinayagam, C. Bergwitz, B. Berger et al., 2011 An integrative approach to ortholog prediction for disease-focused and other functional studies. Bmc Bioinformatics 12.

Huang, W., A. Massouras, Y. Inoue, J. Peiffer, M. Ramia et al., 2014 Natural variation in genome architecture among 205 Drosophila melanogaster Genetic Reference Panel lines. Genome Research 24: 1193-1208.

Huang, W., S. Richards, M. A. Carbone, D. H. Zhu, R. R. H. Anholt et al., 2012 Epistasis dominates the genetic architecture of Drosophila quantitative traits. Proceedings of the National Academy of Sciences of the United States of America 109: 15553-15559.

Jovaisaite, V., L. Mouchiroud and J. Auwerx, 2014 The mitochondrial unfolded protein response, a conserved stress response pathway with implications in health and disease. Journal of Experimental Biology 217: 137-143.

Kain, J. S., C. Stokes and B. L. de Bivort, 2012 Phototactic personality in fruit flies and its suppression by serotonin and white. Proceedings of the National Academy of Sciences of the United States of America 109: 19834-19839.

Kise, Y., and D. Schmucker, 2013 Role of self-avoidance in neuronal wiring. Current Opinion in Neurobiology 23: 983-989.

Klingenberg, C. P., 2019 Phenotypic Plasticity, Developmental Instability, and Robustness: The Concepts and How They Are Connected. Frontiers in Ecology and Evolution 7.

Lajus, D. L., P. V. Golovin, A. O. Yurtseva, T. S. Ivanova, A. S. Dorgham et al., 2019 Fluctuating asymmetry as an indicator of stress and fitness in stickleback: a review of the literature and examination of cranial structures. Evolutionary Ecology Research 20.

Lehmann, F. O., and J. Bartussek, 2017 Neural control and precision of flight muscle activation in Drosophila. Journal of Comparative Physiology a-Neuroethology Sensory Neural and Behavioral Physiology 203: 1-14.

Li, J. F., S. Han, H. J. Li, N. D. Udeshi, T. Svinkina et al., 2020 Cell-Surface Proteomic Profiling in the Fly Brain Uncovers Wiring Regulators. Cell 180: 373-+. 
Li, X. Y., S. MacArthur, R. Bourgon, D. Nix, D. A. Pollard et al., 2008 Transcription factors bind thousands of active and inactive regions in the Drosophila blastoderm. Plos Biology 6: 365-388.

Long, T. A. F., and W. R. Rice, 2007 Adult locomotory activity mediates intralocus sexual conflict in a laboratory-adapted population of Drosophila melanogaster. Proceedings of the Royal Society B-Biological Sciences 274: 3105-3112.

MacArthur, S., X. Y. Li, J. Y. Li, J. B. Brown, H. C. Chu et al., 2009 Developmental roles of 21 Drosophila transcription factors are determined by quantitative differences in binding to an overlapping set of thousands of genomic regions. Genome Biology 10.

Mackay, T. F., and W. Huang, 2018 Charting the genotype-phenotype map: lessons from the Drosophila melanogaster Genetic Reference Panel. Wiley Interdisciplinary Reviews: Developmental Biology 7.

Mackay, T. F. C., S. Richards, E. A. Stone, A. Barbadilla, J. F. Ayroles et al., 2012 The Drosophila melanogaster Genetic Reference Panel. Nature 482: 173-178.

Marcus, J. M., 2001 The development and evolution of crossveins in insect wings. Journal of Anatomy 199: 211-216.

Menezes, B. F., J. Salces-Ortiz, H. Muller, N. Burlet, S. Martinez et al., 2018 An attempt to select non-genetic variation in resistance to starvation and reduced chill coma recovery time in Drosophila melanogaster. Journal of Experimental Biology 221.

Metaxakis, A., S. Oehler, A. Klinakis and C. Savakis, 2005 Minos as a genetic and genomic tool in Drosophila melanogaster. Genetics 171: 571-581.

Milan, M., F. J. Diaz-Benjumea and S. M. Cohen, 1998 Beadex encodes an LMO protein that regulates Apterous LIM-homeodomain activity in Drosophila wing development: a model for LMO oncogene function. Genes \& Development 12: 2912-2920.

Morgante, F., P. Sorensen, D. A. Sorensen, C. Maltecca and T. F. C. Mackay, 2015 Genetic Architecture of Micro-Environmental Plasticity in Drosophila melanogaster. Scientific Reports 5.

Moses, A. M., D. A. Pollard, D. A. Nix, V. N. Iyer, X. Y. Li et al., 2006 Large-scale turnover of functional transcription factor binding sites in Drosophila. Plos Computational Biology 2: 1219-1231.

Mossman, J. A., L. M. Biancani, C. T. Zhu and D. M. Rand, 2016 Mitonuclear Epistasis for Development Time and Its Modification by Diet in Drosophila. Genetics 203: 463-+.

Muhammad, K., S. Reddy-Alla, J. H. Driller, D. Schreiner, U. Rey et al., 2015 Presynaptic spinophilin tunes neurexin signalling to control active zone architecture and function. Nature Communications 6.

Munoz-Munoz, F., V. P. Carreira, N. Martinez-Abadias, V. Ortiz, R. Gonzalez-Jose et al., 2016 Drosophila wing modularity revisited through a quantitative genetic approach. Evolution 70: 1530-1541.

Nagai, T., and K. Mizuno, 2014 Multifaceted roles of Furry proteins in invertebrates and vertebrates. Journal of Biochemistry 155: 137-146.

Nakka, P., B. J. Raphael and S. Ramachandran, 2016 Gene and Network Analysis of Common Variants Reveals Novel Associations in Multiple Complex Diseases. Genetics 204: 783-+. 
Negre, N., C. D. Brown, L. J. Ma, C. A. Bristow, S. W. Miller et al., 2011 A cis-regulatory map of the Drosophila genome. Nature 471: 527-531.

Paul, L., S. H. Wang, S. N. Manivannan, L. Bonanno, S. Lewis et al., 2013 Dpp-induced Egfr signaling triggers postembryonic wing development in Drosophila. Proceedings of the National Academy of Sciences of the United States of America 110: 5058-5063.

Pavlou, H. J., and S. F. Goodwin, 2013 Courtship behavior in Drosophila melanogaster: towards a 'courtship connectome'. Current Opinion in Neurobiology 23: 76-83.

Pellegrino, M. W., A. M. Nargund and C. M. Haynes, 2013 Signaling the mitochondrial unfolded protein response. Biochimica et Biophysica Acta (BBA)-Molecular Cell Research 1833: 410-416.

Pitchers, W., J. Nye, E. J. Marquez, A. Kowalski, I. Dworkin et al., 2019 A Multivariate Genome-Wide Association Study of Wing Shape in Drosophila melanogaster. Genetics 211: 1429-1447.

Purcell, S., B. Neale, K. Todd-Brown, L. Thomas, M. A. R. Ferreira et al., 2007 PLINK: A tool set for whole-genome association and population-based linkage analyses. American Journal of Human Genetics 81: 559-575.

Quijano, J. C., M. J. Stinchfield, B. Zerlanko, Y. Y. Gibbens, N. T. Takaesu et al., 2010 The Sno Oncogene Antagonizes Wingless Signaling during Wing Development in Drosophila. Plos One 5.

Quinto-Sanchez, M., F. Munoz-Munoz, J. Gomez-Valdes, C. Cintas, P. Navarro et al., 2018 Developmental pathways inferred from modularity, morphological integration and fluctuating asymmetry patterns in the human face. Scientific Reports 8.

Roman, A. C., J. Vicente-Page, A. Perez-Escudero, J. M. Carvajal-Gonzalez, P. M. Fernandez-Salguero et al., 2018 Histone $\mathrm{H} 4$ acetylation regulates behavioral inter-individual variability in zebrafish. Genome Biology 19.

Romero-Calderon, R., R. M. Shome, A. F. Simon, R. W. Daniels, A. DiAntonio et al., 2007 A screen for neurotransmitter transporters expressed in the visual system of Drosophila melanogaster identifies three novel genes. Developmental Neurobiology 67: 550-569.

Rutherford, S. L., and S. Lindquist, $1998 \mathrm{Hsp90}$ as a capacitor for morphological evolution. Nature 396: 336-342.

Sadaf, S., O. V. Reddy, S. P. Sane and G. Hasan, 2015 Neural Control of Wing Coordination in Flies. Current Biology 25: 80-86.

Sambandan, D., A. Yamamoto, J. J. Fanara, T. F. C. Mackay and R. R. H. Anholt, 2006 Dynamic genetic interactions determine odor-guided behavior in Drosophila melanogaster. Genetics 174: 1349-1363.

Schindelin, J., I. Arganda-Carreras, E. Frise, V. Kaynig, M. Longair et al., 2012 Fiji: an open-source platform for biological-image analysis. Nature Methods 9: 676-682.

Schnorrer, F., C. Schonbauer, C. C. H. Langer, G. Dietzl, M. Novatchkova et al., 2010 Systematic genetic analysis of muscle morphogenesis and function in Drosophila. Nature 464: 287-291.

Schor, I. E., J. F. Degner, D. Harnett, E. Cannavo, F. P. Casale et al., 2017 Promoter shape varies across populations and affects promoter evolution and expression noise. Nature Genetics 49: 550-+. 
Shirangi, T. R., A. M. Wong, J. W. Truman and D. L. Stern, 2016 Doublesex Regulates the Connectivity of a Neural Circuit Controlling Drosophila Male Courtship Song. Developmental Cell 37: 533-544.

Siepel, A., G. Bejerano, J. S. Pedersen, A. S. Hinrichs, M. M. Hou et al., 2005 Evolutionarily conserved elements in vertebrate, insect, worm, and yeast genomes. Genome Research 15: 1034-1050.

Siepel, A., and D. Haussler, 2005 Phylogenetic hidden Markov models, pp. 325-351 in Statistical methods in molecular evolution. Springer.

Skeath, J. B., and S. B. Carroll, 1991 REGULATION OF ACHAETE-SCUTE GENEEXPRESSION AND SENSORY ORGAN PATTERN-FORMATION IN THE DROSOPHILA WING. Genes \& Development 5: 984-995.

Soto, I. M., V. P. Carreira, E. M. Soto and E. Hasson, 2008 Wing morphology and fluctuating asymmetry depend on the host plant in cactophilic Drosophila. Journal of Evolutionary Biology 21: 598-609.

Spierer, A. N., J. A. Mossman, S. P. Smith, L. Crawford, S. Ramachandran et al., 2020 Natural variation in the regulation of neurodevelopmental genes modifies flight performance in <em>Drosophila</em>. bioRxiv: 2020.2005.2027.118604.

Sztepanacz, J. L., K. McGuigan and M. W. Blows, 2017 Heritable Micro-environmental Variance Covaries with Fitness in an Outbred Population of Drosophila serrata. Genetics 206: 2185-2198.

Tadros, W., S. W. Xu, O. Akin, C. H. Yi, G. J. E. Shin et al., 2016 Dscam Proteins Direct Dendritic Targeting through Adhesion. Neuron 89: 480-493.

Thistle, R., P. Cameron, A. Ghorayshi, L. Dennison and K. Scott, 2012 Contact chemoreceptors mediate male-male repulsion and male-female attraction during Drosophila courtship. Cell 149: 1140-1151.

Thomas, S., X. Y. Li, P. J. Sabo, R. Sandstrom, R. E. Thurman et al., 2011 Dynamic reprogramming of chromatin accessibility during Drosophila embryo development. Genome Biology 12.

Thurmond, J., J. L. Goodman, V. B. Strelets, H. Attrill, L. S. Gramates et al., 2019 FlyBase 2.0: the next generation. Nucleic Acids Research 47: D759-D765.

Tilney, L. G., P. S. Connelly, L. Ruggiero, K. A. Vranich and G. M. Guild, 2003 Actin filament turnover regulated by cross-linking accounts for the size, shape, location, and number of actin bundles in Drosophila bristles. Molecular Biology of the Cell 14: 3953-3966.

Tootle, T. L., D. Williams, A. Hubb, R. Frederick and A. Spradling, 2011 Drosophila Eggshell Production: Identification of New Genes and Coordination by Pxt. Plos One 6.

Tsuzuki, S., M. Ochiai, H. Matsumoto, S. Kurata, A. Ohnishi et al., 2012 Drosophila growth-blocking peptide-like factor mediates acute immune reactions during infectious and non-infectious stress. Scientific Reports 2.

Turner, T. L., P. M. Miller and V. A. Cochrane, 2013 Combining Genome-Wide Methods to Investigate the Genetic Complexity of Courtship Song Variation in Drosophila melanogaster. Molecular Biology and Evolution 30: 2113-2120.

Valen, L. V., 1962 A study of fluctuating asymmetry. Evolution 16: 125-142. 
822 Vogt, G., 2015 Stochastic developmental variation, an epigenetic source of phenotypic 823 diversity with far-reaching biological consequences. Journal of Biosciences 40: 824 159-204.

825 Vogt, G., M. Huber, M. Thiemann, G. van den Boogaart, O. J. Schmitz et al., 2008

$826 \quad$ Production of different phenotypes from the same genotype in the same

827 environment by developmental variation. Journal of Experimental Biology 211: 510-523.

Wagner, A., 2008 Robustness and evolvability: a paradox resolved. Proceedings of the Royal Society B-Biological Sciences 275: 91-100.

Wasbrough, E. R., S. Dorus, S. Hester, J. Howard-Murkin, K. Lilley et al., 2010 The Drosophila melanogaster sperm proteome-II (DmSP-II). Journal of proteomics 73: 2171-2185.

Wrischnik, L. A., J. R. Timmer, L. A. Megna and T. W. Cline, 2003 Recruitiment of the proneural gene scute to the Drosophila sex-determination pathway. Genetics 165: 2007-2027.

Yatsu, J., M. Hayashi, M. Mukai, K. Arita, S. Shigenobu et al., 2008 Maternal RNAs encoding transcription factors for germline-specific gene expression in Drosophila embryos. International Journal of Developmental Biology 52: 913923.

Yu, J. Y., M. I. Kanai, E. Demir, G. Jefferis and B. J. Dickson, 2010 Cellular Organization of the Neural Circuit that Drives Drosophila Courtship Behavior. Current Biology 20: 1602-1614.

zur Lage, P., F. G. Newton and A. P. Jarman, 2019 Survey of the Ciliary Motility Machinery of Drosophila Sperm and Ciliated Mechanosensory Neurons Reveals Unexpected Cell-Type Specific Variations: A Model for Motile Ciliopathies. Frontiers in Genetics 10. 